\title{
Interpretação e Modelagem 3D das Anomalias Magnéticas do Alvo Candonga - Guanhães, MG.
}

Mulatti, J. C.

Departamento de Geologia - Escola de Minas/UFOP

Copyright 2016, SBGf - Sociedade Brasileira de Geofísica

Este texto foi preparado para a apresentação no VII Simpósio Brasileiro de Geofísica, Ouro Preto, 25 a 27 de outubro de 2016. Seu conteúdo foi revisado pelo Comitê Técnico do VII SimBGf, mas não necessariamente representa a opinião da SBGf ou de seus associados. É proibida a reprodução total ou parcial deste material para propósitos comerciais sem prévia autorização da SBGf.

\section{Resumo}

Tem-se observado na literatura que depósitos ferríferos possuem algumas propriedades físicas especiais que os tornam passíveis de prospecção por métodos geofísicos. Este fato permite que os contrastes em tais propriedades gerassem assinaturas anômalas nos campos físicos correspondentes, o que torna possível a prospecção de tais depósitos por métodos geofísicos. Entre estas propriedades está a magnetização, que viabiliza o uso de medições da intensidade do campo magnético para mapear os contrastes anômalos e decodificá-los em informações úteis ao entendimento das estruturas e tipos litológicos locais.

\section{Introdução}

A área a ser mensurada por meio de levantamento magnetométrico terrestre situa-se no município de Guanhães, alvo Candonga, na porção central de Minas Gerais, sendo que a cidade de Guanhães pode ser acessa pelas vias BR 120 e BR259 (Figura 1). A modelagem dos dados magnetométricos tem como objetivo a localização de corpos ricos em minerais de ferro e associados à magnetita (sã ou alterada), ao mesmo tempo verificar seus contatos magnéticos referentes aos limites do corpo de minério. Os quais não são conhecidos através das sondagens, uma vez que não existe sondagem na área, dessa forma não são conhecidos em subsuperfície os limites das encaixantes, bem como a possível posição e intercalações da formação. Além de determinações de depósitos e dos deslocamentos horizontais (laterais) e verticais dos limites das assinaturas magnéticas por meio de filtragem do espectro de frequência, procura-se obter as profundidades dos topos das fontes magnéticas e seu deslocamento vertical, a fim de mensurar as dimensões dos depósitos.

Ressalta-se que por meio da assinatura magnética obtida através da filtragem do espectro de frequência, onde pode determinar a posição do corpo de minério ou mesmo deposito, sem considerar a posição exata da encaixante, uma vez que há influência de fontes em subsuperfície. Os processos de intemperismo são superficiais e não influencia em escala macro a zona de contato. O que define a posição das intercalações das zonas de contato é o teor de mineral de magnetita que faz parte da rocha, dessa forma distinguir as fácies de minério (+ hematita - magnetita) da rocha pré-enriquecimento e/ou hidrotermalismo é difícil, no entanto o que se busca é a anomalia como um todo. Portanto, pode-se confiar no modelo em relação ao contato magnético (extensão lateral) por meio do espectro de frequência onde se determina a posição da formação ferrífera (magnetita/hematita/itabirito) e o depósito de minério inserido à encaixante, mas se deve estabelecer um critério com relação à cota a qual se estende o minério, usando principalmente a informação geológica.

\section{Metodologia/ Problema Investigado}

Os dados do levantamento de geofísica terrestre e aerogeofísico sobre as áreas cujas anomalias estão associadas aos corpos de formação ferrífera (magnetita, hematita e itabirito) de Guanhães foram utilizados para a realização dos trabalhos de interpretação e modelagem. Esses, então, foram empregados para efeito de modelagem 3D. A anomalia magnética que representam os corpos de Candonga Norte apresenta em seu maior diâmetro $150 \mathrm{~m}$ e um comprimento aproximado de $350 \mathrm{~m}$.

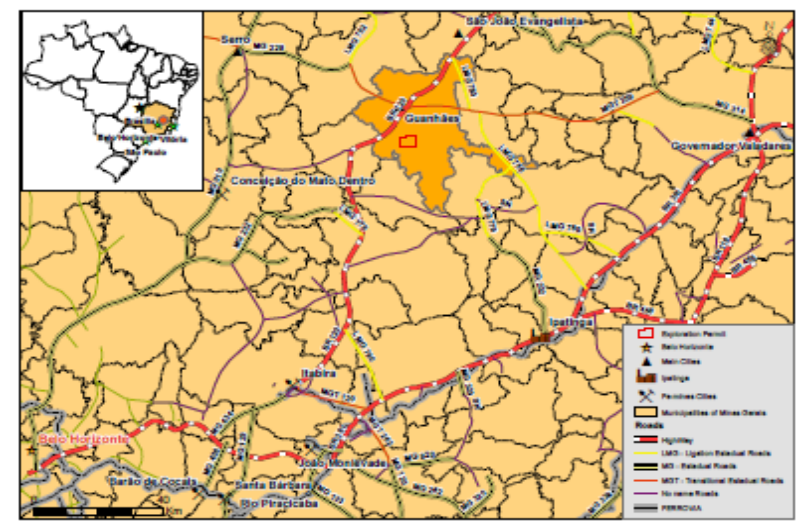

Figura 1 - Localização geográfica da área as principais vias de acesso e municípios.

A anomalia apresenta comportamento da intensidade magnética heteromórfica com uma variação do espectro de frequência magnética intensa. Para o campo magnético total o valor mínimo é 9.4121 nT e o valor máximo de 99.7841 nT o que evidencia uma variação de 90.372 nT. A (Tabela 1) ilustra um sumário estatístico para o canal do campo magnético total reduzido ao IGRF restrito à área de Candonga $\mathrm{Mg}$.

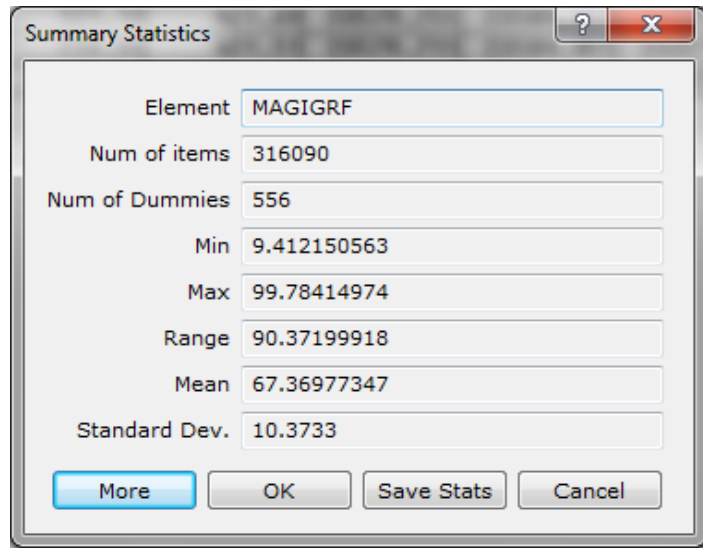

Tabela 1 - Sumario estatístico. 


\section{Resultados}

Este Complexo representa uma parte crustal consolidada no Mesoarqueano, que é constituída fundamentalmente por uma associação de complexos granito-gnáissicos e cinturões verdes (greenstone belts). São formadas por segmentos crustais antigos onde são identificados os blocos: Quadrilátero Ferrífero (QF), Guanhães e Porteirinha, em Minas Gerais (Bizzi et al. 2003). Os blocos do QF, com suas estruturas em domos e quilhas, e Guanhães, substrato da faixa Neoproterozóica Araçuaí, estão conectados entre si e forma uma expressiva massa crustal mesoarqueana, retrabalhada pelas orogêneses Transamazônica e Brasiliana (Bizzi et al. 2003), (Figura 2).

O que chama a atenção na análise dos temas que se seguirão, são as duas áreas com valores magnéticos positivos anômalos: uma na região centro-norte da área e outro na região sul da mesma, descontínuas ao redor do meridiano de $722.40 \mathrm{~m} \mathrm{E}$ (Figura 3 ).

A imagem da CAT mostra que há cinco grandes seguimentos com valores magnéticos anômalos (positivos), paralelos mais não colineares. Todos têm direção NW-SE.

Paralelamente aos seguimentos central e principalmente no sul aparecem anomalias similares e igualmente paralelas as centrais à malha de amostragem. Outras aparecem nas extremidades dos perfis (como aquelas ao sul do ramo sul e ao norte do ramo central; Figura 3 ).

Brito Neves et al. (1995) denomina de Tafrogênese Estateriana ao fenômeno global de extensão crustal e eventos conexos relacionados a "manto ativado e litosfera ativada". Entre 1,8 e 1,6 Ga, o regime extensional do período Estateriano foi responsável pela ruptura da crosta continental e pela formação de sistema de riftes intracontinentais, sucedidos por intrusão e extrusão de rochas félsicas, piroclásticas e vulcanoclásticas subaéreas e seguidas de sedimentação psamítica de ambiente continental.

Na porção sul da Província, região do município de Guanhães (MG), a Suíte Intrusiva Borrachudos (MG) representa o plutonismo granítico tipo A, intraplaca, na forma de batólitos, stocks e diques de granito e quartzo.

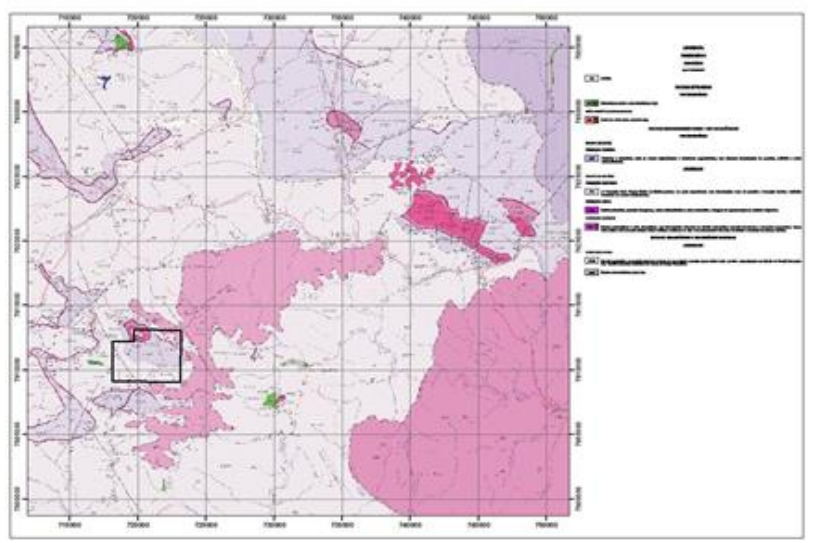

Figura 2 - Mapa da geologia local do Alvo Candonga. Mapa Geológico da Folha Guanhães com a localização da área de estudo, escala 1:200.000. Fonte CODEMIG (2003).

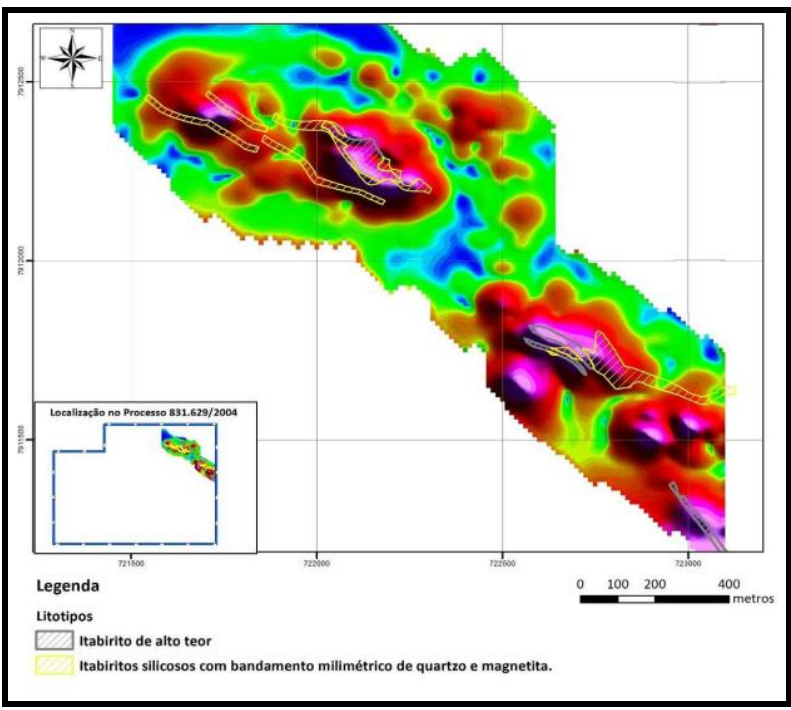

Figura 3 - A concordância entre as indicações ferríferas no mapa geológico em vários trechos da estrutura magnética.

Uma primeira aproximação quanto as profundidade das fontes pode se conseguida com análise dos sinais magnéticos medidos domínio de Fourier. Estes sinais estão aqui representados em termos das frequências espaciais que o compõem. O estudo do espectro de potência dos dados do Alvo Candonga aponta a presença de duas famílias de fontes presentes na área levantada (Figura 3):

i. Uma mais profunda, ao redor de $100 \mathrm{~m}$;

ii. Outra mais superficial, a menos de $50 \mathrm{~m}$.

A modelagem 3D a partir da anomalia magnética referente aos corpos situados em Candonga norte foi realizada por meio do módulo proprietário (Geosoft), a partir das anomalias magnéticas. As anomalias foram amostradas por meio de células tendo dimensões de $25 \mathrm{~m}$, de maneira que a anomalia fosse amostrada em toda a sua extensão, cujo objetivo foi obter informações da dispersão dos minerais ferromagnéticos ao longo do complexo e mensurar sua distribuição em subsuperfície.

Os perfis foram construídos ao longo dos intensos gradientes magnéticos e nesse buscando as zonas anômalas apresentadas pelo tratamento dos dados de magnetometria e gamaespectrometria, de onde se possam realizar linhas para a malha de sondagem.

O método permite a integração de outras informações, como, por exemplo: os dados de sondagem ao perfil magnético medido, sendo assim o modelo geológico-geofísico seriam criados com base geológica e depois modelados pela resposta magnetométrica a partir dos perfis magnético. Esta interação permitiria que o modelo final abarcasse parâmetros reais e que se estabelecesse com vínculos e não somente em um modelo geofísico. Não obstante, esse modelo geofísico é a representação das assinaturas dos métodos geofísicos interpretados a partir das assinaturas magnéticas e radiométricas. Os quais são as respostas dos teores de minerais ferromagnéticos, ferrimagnéticos e elementos radiogênicos contidos em cada tipo de rocha. 
Para a construção dos parâmetros e início da modelagem dos corpos magnéticos é informado ao módulo de inversão o grid do campo magnético (resposta geofísica). Quando traçado, então um sistema de coordenadas locais é gerado, com uma densidade de informações bastante alta, com amostragem de 25 metros em 25 metros, sobre o magnetismo do campo terrestre e de topografia. Após a definição destes parâmetros, os dados geológicos obtidos da interpretação são integrados no perfil e, portanto, é realizada uma interpretação geofísica 3D. Após a interpretação geológica as informações de susceptibilidades magnéticas obtidas a partir da tabela incorporadas ao modelo criado. (Figuras 4 a 6 ).

\section{Discussão e Conclusões}

Usamos os dados magnetométricos e gamaespectrométricos para o processamento geofísico, a fim de obter assinaturas anômalas que estivessem espacialmente e geometricamente vinculados a alvos magnéticos de minério de ferro. E dentro desse escopo que se pudessem caracterizar zonas condicionadoras de reserva/depósitos de ferro. Esse é um projeto ousado, já que as zonas ora são muito magnéticas, ora são pouco magnéticas, que nem sempre são ricas em magnetita que torna a delimitação/separação um trabalho demorado e o contato muito difícil, mas que pode ser feita por meio dos espectros de frequências dos sinais magnéticos. Haja vista que a suscetibilidade magnética apresenta um espectro mui pequeno para torná-lo um diferencial na modelagem 3D.

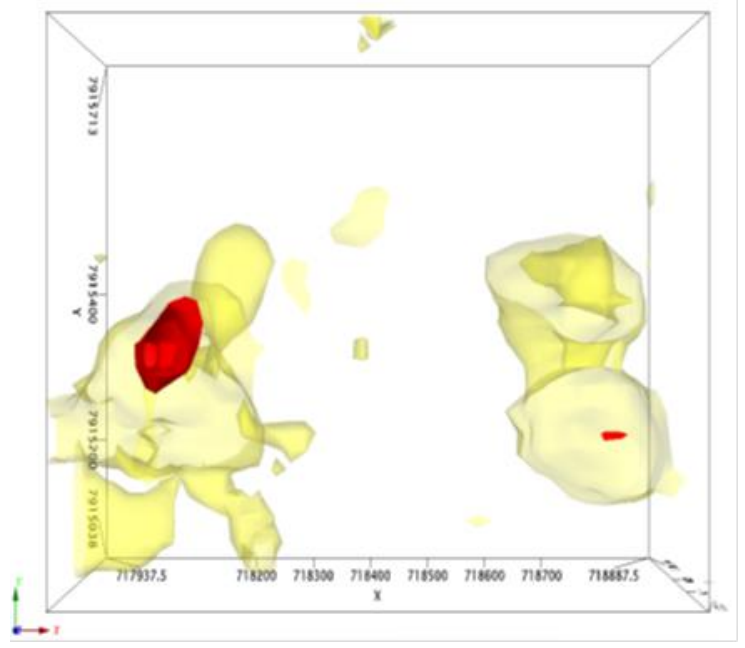

Figura 4 - Modelagem geofísica da anomalia magnética de Candonga Norte. Em vermelho está a zona mais intensa magneticamente relacionada à estrutura de ferro e em amarelo zonas de contato.

Dessa forma o processamento de dados magnetométricos com o objetivo de definir os prováveis limites do minério de ferro, só pode ser logrado mediante aplicação de filtros. Uma vez que o baixo contraste das suscetibilidades, entre as rochas encaixantes Itabirito e os depósitos de ferro, os quais são pouco enriquecidos em materiais magnéticos (nos corpos de minério), é dificultada devido ao gradiente do teor em magnetita. Dessa forma se faz necessário a aplicação de outras metodologias para determinar os ambientes mineralizados. O modelo 3D das anomalias magnéticas são resultados das filtragens do banco de dados buscando obter comprimentos de onda definidos para cada profundidade de interesse. Essas frequências variam desde as altas (corpos rasos), intermediárias (corpos intermediários) e baixas frequências (corpos profundos). Nesse contexto construímos um modelo que fosse geral e que representasse a zona mineralizada. As (Figuras 5 e 6 ), abaixo mostram os perfis com suas respectivas propriedades relativos a suas frequências que são as chaves para obter uma modelagem de qualidade e representativas.

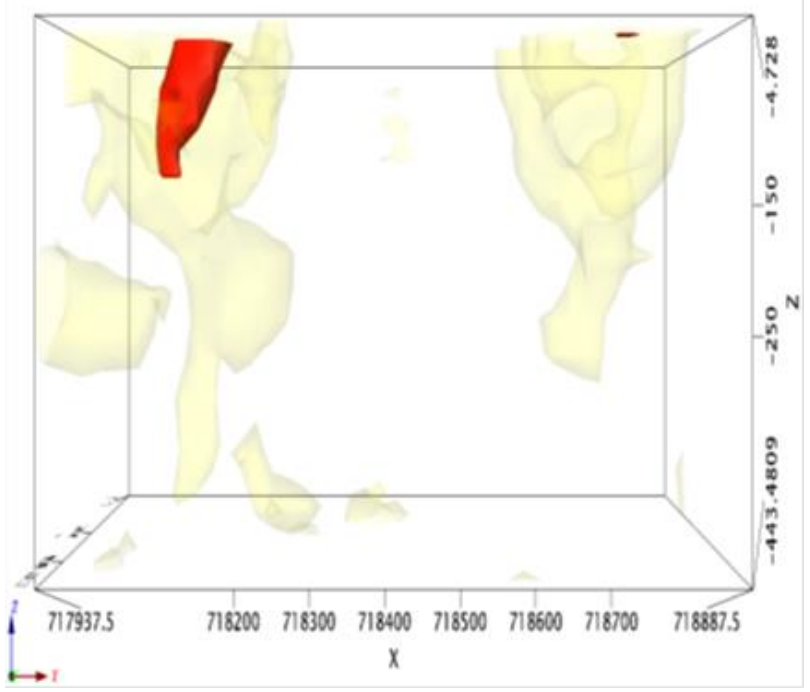

Figura 5 - Apresentação das informações dos perfis magnéticos, sua interpretação geológica 3D das profundidades.

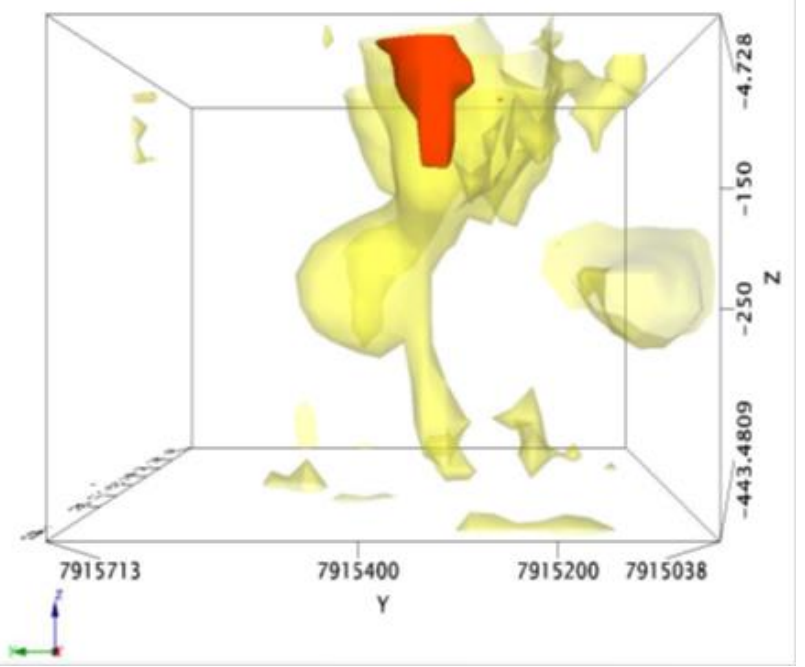

Figura 6 - Perfis lateral do modelo resultante da anomalia magnética de Candonga Norte.

Os domínios geofísicos identificados (Figura 3) são responsáveis pelas assinaturas de base que produzem os relevos e assinaturas magnéticas observadas e analisadas. Estes encerram fontes geradoras com características físicas similares. Os campos geofísicos mostram nuances das diferentes propriedades físicas que estas fontes apresentam, Exibem assim, com riqueza de detalhes, aspectos que complementam e detalham a geologia mapeada, fornecendo informações sobre o comportamento espacial de suas unidades, em especial aqui, o 
comportamento espacial do que seria o alvo das pesquisas: formações ferríferas.

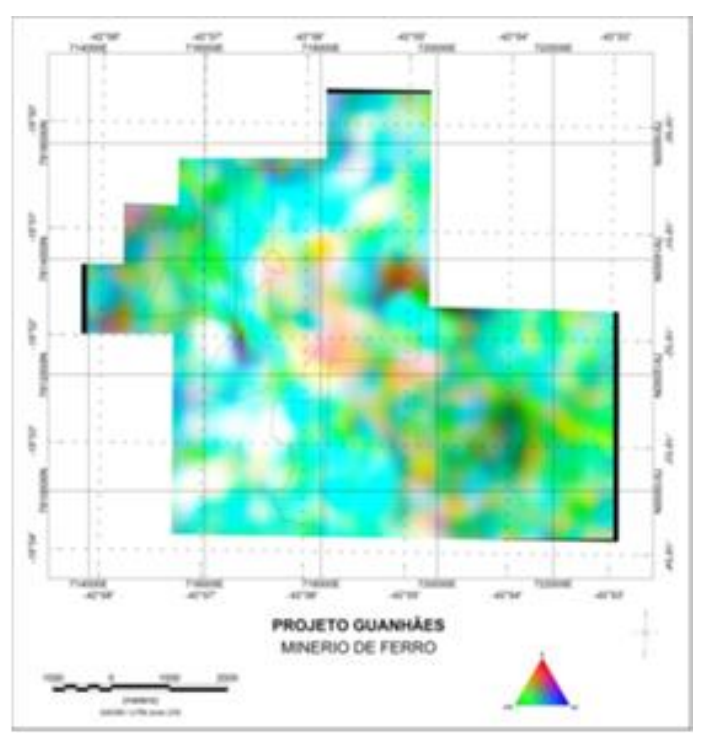

Figura 7 - Composição Ternária RGB.

Do mesmo modo, as estruturas geofísicas (dobras e falhamentos associados) interpretadas representam assinaturas que revelam aspectos do intrincado arcabouço geológico e estrutural local, onde estão as fontes responsáveis pelas assinaturas magnéticas reveladas.

\section{Agradecimentos}

Agradeço Centaurus Brasil Mineração Ltda pela permissão de utilizar os dados geológicos e geofísicos para fins acadêmicos e a Geofbras Exploração Geofísicas Ltda.

\section{Referências}

Bizzi, L, A., Schobbenhaus, C., Vidotti, R, M., e Gonçalves, J, H, (Eds.), 2003, Geologia, Tectônica e Recursos Minerais do Brasil: texto, mapas \& SIG, Brasília-DF, CPRM - Serviço Geológico do Brasil, 692p.

Brito Neves, B, B., Sá, J. M. e Nilson. A. A., Botelho, N. F., 1995, A Tafrogênese Estateriana nos blocos paleoproterozóicos da América do Sul e processos subsequentes, in: Bizzi, L. A.; Schobbenhaus, C.; Vidotti, R. M.; Gonçalves, J. H. 2003, Geologia, tectônica e Recursos Minerais do Brasil: texto, mapas \& SIG, Brasília-DF, CPRM - Serviço Geológico do Brasil, 692p.

CODEMIG / UFMG, 1996, Projeto Espinhaço, Folha Guanhães (Escala de 1:100,000): Compilação por J. H. Grossi Sad, Dardenne, M. A.; Schobbenhaus, C., 2001, Metalogênese do Brasil: Brasília, Ed. Universidade de Brasília, 392p.

Grossi Sad, J. H., Magalhães, J. M. M. e Carelos, P. M., 1989, Geologia do Distrito de Guanhães, Minas Gerais, Belo Horizonte, DOCEGEO - GEOSOL, Relatório Interno, $252 \mathrm{p}$.

Grossi Sad J. H., 1993 - Geologia da Folha Guanhães, Minas Gerais. Projeto Espinhaço, UFMG, Belo Horizonte, MG. $117 p$. 